Original Research Paper

\title{
Numerical Investigation on Turbulent Forced Convection in Heating Channel Inserted with Discrete V-Shaped Baffles
}

\author{
${ }^{1}$ Amnart Boonloi and ${ }^{2}$ Withada Jedsadaratanachai \\ ${ }^{I}$ Department of Mechanical Engineering Technology, College of Industrial Technology, \\ King Mongkut's University of Technology North Bangkok, Bangkok 10800, Thailand \\ ${ }^{2}$ Department of Mechanical Engineering, Faculty of Engineering, \\ King Mongkut's Institute of Technology Ladkrabang, Bangkok 10520, Thailand
}

\author{
Article history \\ Received: 02-11-2015 \\ Revised: 01-04-2016 \\ Accepted: 02-04-2016 \\ Corresponding Author: \\ Withada Jedsadaratanachai \\ Department of Mechanical \\ Engineering, Faculty of \\ Engineering, King Mongkut's \\ Institute of Technology \\ Ladkrabang, Bangkok 10520, \\ Thailand \\ Email:kjwithad@kmitl.ac.th
}

\begin{abstract}
The numerical examinations on flow visualization, heat transfer characteristic and performance improvement in a square duct inserted with discrete $\mathrm{V}$-shaped baffles $(D V B)$ are reported. The $D V B$ is designed to reduce the pressure loss when compared with the V-shaped baffle. The influences of the flow blockage ratios $(b / H, B R=0.05-0.20)$, V-tip directions (V-Downstream and V-Upstream) are investigated for Reynolds number, $R e=3000-20,000$, with a single pitch ratio and flow attack angle of 1 and $30^{\circ}$, respectively. As the results, the $D V B$ can generate the vortex flow and impinging flow through the test section that assists to develop the thermal efficiency. The augmentations on the heat transfer coefficient and pressure drop are around 2.5-5.75 and 4-22.5 times above the smooth duct, respectively. The best thermal efficiency in forms of thermal enhancement factor, $T E F$, around 2.32 is detected at $R e=3000, B R=0.10$ and V-Upstream.
\end{abstract}

Keywords: Baffle, Flow Visualization, Heat Transfer, Numerical Study, Thermal Performance

\section{Introduction}

Heat exchanger is important equipment, which always used in many industries and engineering works. The increment of the thermal efficiency in the heat exchanger can help to save costs for the production process and also help to reduce the size of the heat exchanger.

The developments of the heat exchangers are divided into two techniques; active and passive methods. The thermal improvement in the heat exchanger with the passive technique is a famous mode due to not require additional power into the heating system. The main purpose of the passive method is to generate the vortex flow, swirling flow, impinging flow, etc., that enhance the heat transfer rate and efficiency.

The V-shaped baffle/rib is a type of vortex generators, which always inserted in a heating tube or channel to augment thermo-hydraulic performance. The parameters such as flow attack angle, blockage ratio, pitch ratio, etc., of the $\mathrm{V}$-shaped baffle have effect for the flow structure and heat transfer behavior in the heat exchanger. The influences of the parameters for the $\mathrm{V}$-shaped baffle in the heat exchanger had been investigated on both numerical and experimental methods. The experimental result has more reliability than those from the numerical result. But, if the understanding of the mechanisms in the heating section is focused, the researchers must choose the numerical study.

Jedsadaratanachai et al. (2015) examined the laminar forced convection in a circular tube placed with Vbaffles for the Reynolds number, $R e=100-2000$. They reported that the $B R=0.2$ and 0.25 for the $\mathrm{V}$ Upstream and V-Downstream, respectively, give the optimum thermal enhancement factor around 3.2. Rajaseenivasan et al. (2015) compared the thermal performance between circular and V-type turbulators that placed on an absorber plate of a solar air heater for $R e=6000-12,000$. They presented that the efficiency increases with enhancing the Reynolds number and number of the turbulators. They also claimed that the thermo-hydraulic efficiency increases around 63\%. Noothong et al. (2015) presented the turbulent forced convection in a square duct heat exchanger with discrete V-Finned Tapes $(D F T)$ at $R e=4000-25,000$. The blockage ratios $(0.075,0.1,0.15$ and 0.2$)$, pitch ratios $(0.5,1.0,1.5$ and 2.0$)$ with a single flow attack angle of 
$45^{\circ}$ for the DFT were investigated. They reported that the maximum values on the Nusselt number and friction loss are found at $B R=0.2$ and $P R=0.5$, while the best thermal efficiency is found at $B R=0.1$ and $P R=1.5$. Promvonge (2015) experimentally studied the heat and flow profiles in a square duct with quadruple $\mathrm{V}$-finned twisted tapes for $R e=4000-30,000$. The effects of the relative fin height and relative fin pitch were studied with a single flow attack angle of $30^{\circ}$ and a twisted ratio of 4 . Promvonge (2015) stated that the thermal enhancement factor is found to be the best around 1.75. Jedsadaratanachai and Boonloi (2014a) selected $30^{\circ}$ double V-baffles to augment the thermal performance in a heating duct. The effects of the baffle parameters (blockage ratio and pitch ratio) were investigated for the Reynolds number, $R e=100-1200$, with a single flow attack angle of $30^{\circ}$. They concluded that the best thermal performance is around 3.2 at $B R=0.1, P R=1$ and $R e=1200$. Alam et al. (2014a) carried out to study the heat transfer and friction loss for $\mathrm{V}$-shaped blockages with perforation holes at $R e=2000-20,000$ in a solar air heater channel. The different hole shape, relative blockage height, relative pitch, flow area ratio and flow attack angle were investigated. Alam et al. (2014b) experimentally investigated on the heat transfer improvement in a solar air heater channel fitted with $60^{\circ} \mathrm{V}$-shaped perforated blocks for $R e=2000$ 20,000 . They summarized that the enhancements of the Nusselt number and friction factor are around 6.76 and 28.84 times above the smooth channel, respectively. Karwa and Chitoshiya (2013) indicated that the $60^{\circ} \mathrm{V}$ down discrete rib in a solar air heater enhances the thermal performance around 12.5-20\%. Promvonge et al. (2012a) improved a heating channel with $45^{\circ} \mathrm{V}$-shaped baffles. They stated that the $B R=0.2$ with $P R=1.5$ performs the highest thermal performance around 3.8 with the Nusselt number around 14 times over the smooth channel. Promvonge et al. (2011) selected $60^{\circ}$ discrete $\mathrm{V}$-rib to develop the thermo-hydraulic performance in a heating duct at turbulent regime, $R e=10,000-25,000$. They found that the periodic profile on flow and heat transfer in the duct is around $x / D=7-11$ downstream of the entry. They also presented that the $B R=0.0725$ provides the best thermo-hydraulic efficiency around 1.8 with the Nusselt number around 4 times above the smooth channel. Promvonge and Kwankaomeng (2010) improved the thermal efficiency in an $A R=2$ channel with $45^{\circ} \mathrm{V}$-baffles for $R e=100-1200$. The Vbaffles were located on the upper-lower surfaces of the channel with staggered organization. They stated that the best case, which gives the TEF around 2.6, is found at $B R=0.15$ for V-Upstream. Promvonge (2010) experimentally studied the heat transfer characteristic and friction loss in a rectangular channel $(A R=10)$ with $60^{\circ}$ V-baffles for $R e=5000-25,000$. The influences of the blockage ratios $(B R=0.1,0.2$ and 0.3$)$ and pitch ratios $(P R=1,2$ and 3$)$ were examined with a single transverse pitch around $2 H$ ( $H$ is the channel height). Lee et al. (2009) selected continuous V-shaped ribs with $60^{\circ}$ attack angle and multiple (staggered) Vshaped ribs with $45^{\circ}$ attack angle in various aspect ratios of rectangular channels to augment the heat transfer rate. They concluded that the influence of the aspect ratio is more significant for the continuous Vshaped ribs than the multiple V-shaped ribs. Boonloi and Jedsadaratanachai (2014a) presented the thermal improvement of a square channel heat exchanger with modified V-shaped baffle. The use of reformed Vshaped baffle in a square duct was also reported by Jedsadaratanachai and Boonloi (2014b).

In the present research, the $\mathrm{V}$-shaped baffle is modified with the main aim as follows:

- To keep similarly flow structure and efficiency as the V-shaped baffle

- To decrease the pressure loss in the heating system when comparing with the V-baffle

- To reduce the low heat transfer regime; four edges of the duct, behind the baffle

- To present a new design of the vortex generator, which easy forming and installing in the real system (the concept for installation is stated by Promvonge et al., 2012b)

The influences of the blockage ratios $(b / H, B R=$ $0.05-0.20$ ) and flow directions (V-Downstream and VUpstream) are numerically examined with the Reynolds number founded on the channel-hydraulic diameter, $R e=$ $3000-20,000$. The pitch ratio of 1 and the flow attack angle of $30^{\circ}$ are selected for the present study due to the best thermal efficiency was found at this point (Boonloi and Jedsadaratanachai, 2014b). The computational solutions are reported as the mechanisms of flow and heat transfer in the test duct when installing with the Discrete V-Shaped Baffles $(D V B)$. The numerical method can save costs for the investigation process and also help to describe the mechanisms in the heating system. However, the researcher must be sure that the computational domain has high reliability and realistically when examining with the numerical investigation.

\section{Physical Model}

Figure 1 presents the $30^{\circ} \mathrm{DVBs}$ insert in the square duct heat exchanger on the opposite sides with a pitch ratio $(L / H$ or $P R)$ of 1 and inline arrangement. The smooth plate, which is inserted in the middle of the duct, is used to help the stability of the vortex generators when installing in the system. The hydraulic diameter, $D_{h}$, of the square duct is equal to $H=0.05 \mathrm{~m}$ (duct height). The blockage ratios $(b / H$ or $B R=0.05-0.20), \quad \mathrm{V}$-tip pointing (V-tip pointing 
downstream called "V-Downstream" and V-tip pointing upstream called "V-Upstream"), are studied for the Reynolds number, $R e=3000-20,000$. The gap ratio between the duct walls and the $D V B$ is defined as $e / H=0.01$. The computational domain of the $D V B$ in the heating duct is depicted in the Fig. 2.

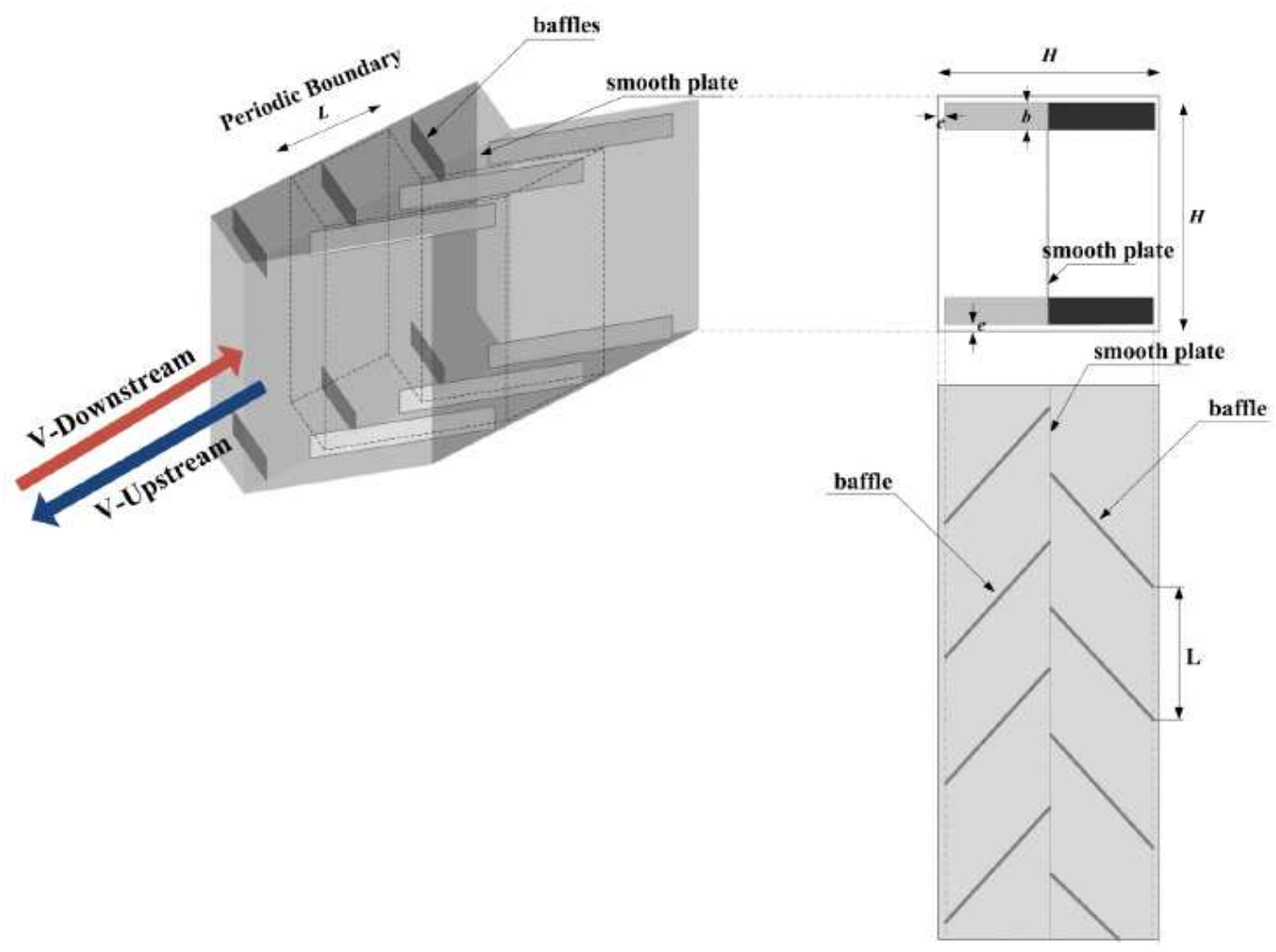

Fig. 1. Square channel inserted with $D V B S$

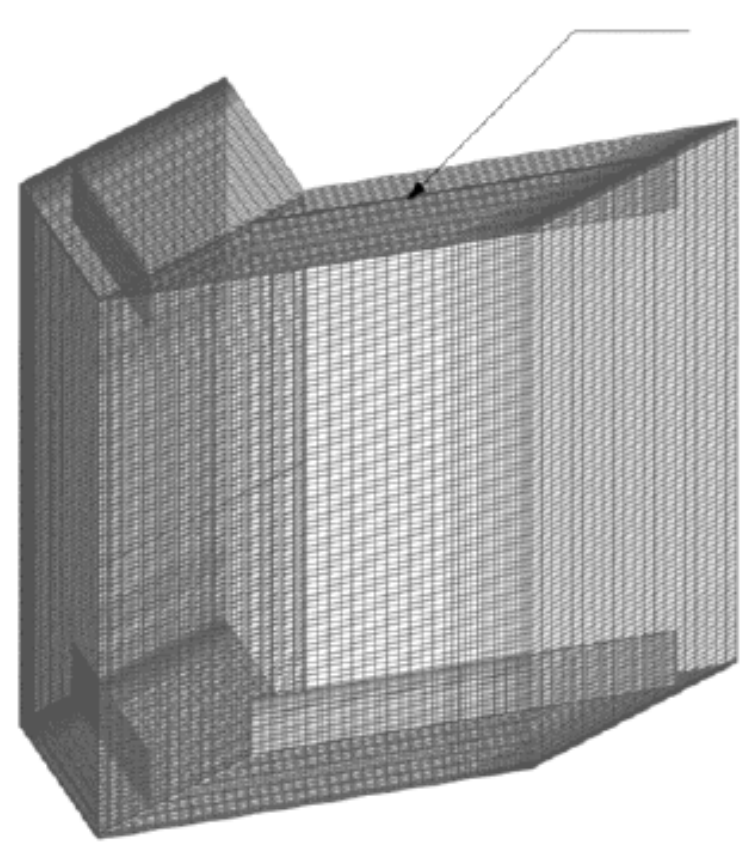

baffle

Fig. 2. Computational domain 


\section{Mathematical Foundation}

The incompressible turbulent flow with steady operation in three dimensions and heat transfer characteristic in the square duct are governed by the continuity, momentum and energy equations. The natural convection, viscous dissipation, body forces and radiation heat transfer are ignored.

The realizable $k-\varepsilon$ turbulent model is selected for the present investigation. The SIMPLE algorithm and the finite volume method (Patankar, 1980) are used to evaluate the current problem. The energy equation is measured to be converged when the normalized residual values are less than $10^{-9}$, while the others are lower than $10^{-5}$.

The important parameters are calculated as follows:

$$
\begin{aligned}
& \mathrm{Re}=\frac{\rho u_{0} D_{h}}{\mu} \\
& f=\frac{(\Delta P / L) D_{h}}{2 \rho \bar{u}^{2}} \\
& N u_{x}=\frac{h_{x} D_{h}}{k} \\
& N u=\frac{1}{A} \int N u_{x} d A \\
& T E F=\left.\frac{h}{h_{0}}\right|_{p p}=\left.\frac{N u}{N u_{0}}\right|_{p p}=\left(\frac{N u}{N u_{0}}\right) /\left(\frac{f}{f_{0}}\right)^{1 / 3}
\end{aligned}
$$

The Nusselt number and the friction factor for the smooth duct are presented as $N u_{0}$ and $f_{0}$, respectively.

\section{Boundary Condition and Assumption}

No-slip wall condition is set for all sides of the duct heat exchanger and the $D V B$ s. Constant heat flux around $600 \mathrm{~W} / \mathrm{m}^{2}$ is applied to the duct walls. The adiabatic wall condition or insulator is used for the baffles. The air $(P r=0.07)$ as test fluid with constant properties at $300 \mathrm{~K}$ flows into the duct heat exchanger. The periodic condition is set for inlet and outlet of the heating channel due to the heat and flow profiles repeat itself from one to another module when installing with array of the vortex generators.

\section{Numerical Result}

The numerical results of the $D V B$ s in the square duct are separated into four parts; validation, flow visualization, heat transfer characteristic and performance assessment. The flow and heat transfer behaviors are selected to present the mechanisms in the duct heat exchanger.
Table 1. Grid independence

\begin{tabular}{lrlll}
\hline & & \multicolumn{3}{c}{ Error (\%) } \\
$\begin{array}{l}\text { Grid } \\
\text { number }\end{array}$ & \multicolumn{1}{c}{$N u$} & $f$ & $\mathrm{~N} u$ & $f$ \\
\hline 619400 & 106.27560 & 0.984121 & 0.000 & 0.00 \\
418500 & 106.26530 & 0.983614 & 0.001 & 0.005 \\
352000 & 106.24410 & 0.982881 & 0.030 & 0.120 \\
232400 & 105.48630 & 0.978793 & 0.740 & 0.540 \\
187200 & 102.75770 & 0.970982 & 3.310 & 1.335 \\
127500 & 98.06728 & 0.954250 & 7.723 & 3.035 \\
81600 & 90.05237 & 0.953072 & 15.265 & 3.155 \\
62700 & 88.74860 & 0.943267 & 16.500 & 4.153 \\
42000 & 79.95333 & 0.937644 & 24.767 & 4.723 \\
\hline
\end{tabular}

\section{Numerical Validation}

The validations of the computational domain can be divided into three sections; grid independence, verification with the smooth tube and verification with the experimental results.

The square duct with the $D V B \mathrm{~s}$ at $B R=0.10, P R=1$ and $R e=8000$ is selected to test the grid independence. The hexahedral mesh is used for all domains. The numbers of grid cells for the computational domain; $42000,62700,81600,127500,187200,232400,352000$, 418500 and 619400, are compared on the Nusselt number and friction factor. It is found that the grid number around 232400 cells gives deviations on the Nusselt number and friction factor around \pm 0.74 and $\pm 0.54 \%$, respectively, in comparison with the 619400 cells. Considering on time and precision results, the grid number around 232400 is selected for the current computational domain in all cases. The grid independence for the present investigation is displayed as Table 1 .

The verifications of the smooth square duct are performed by compared between the present results with the values from correlations on both the Nusselt number and friction factor. The Realizable $k-\varepsilon$ and SST $k-\omega$ models are also compared in this part. As the results, it is found that the Realizable $k-\varepsilon$ model provides the maximum deviations on the Nusselt number and friction factor around 4.27 and 5.4\%, respectively, when compared with the values from the correlations. The verifications with the smooth square duct for the Nusselt number and friction factor are reported as the Fig. 3a and b, respectively.

Figure 4 presents the comparisons of the Nusselt number and friction factor between the numerical and experimental results (Suwannapan et al., 2011) for the square channel with $45^{\circ}$ inclined baffles at $B R=0.1$ and $P R=1$ (due to the experimental investigation for the square channel inserted with $D V B$ has rarely been reported). The variations of the Nusselt number and friction factor are found to be maximum around 2 and $8 \%$, respectively. As the results in this part, it can be concluded that the current model is reliable to predict the flow configuration and heat transfer characteristic in the square duct heat exchanger. 


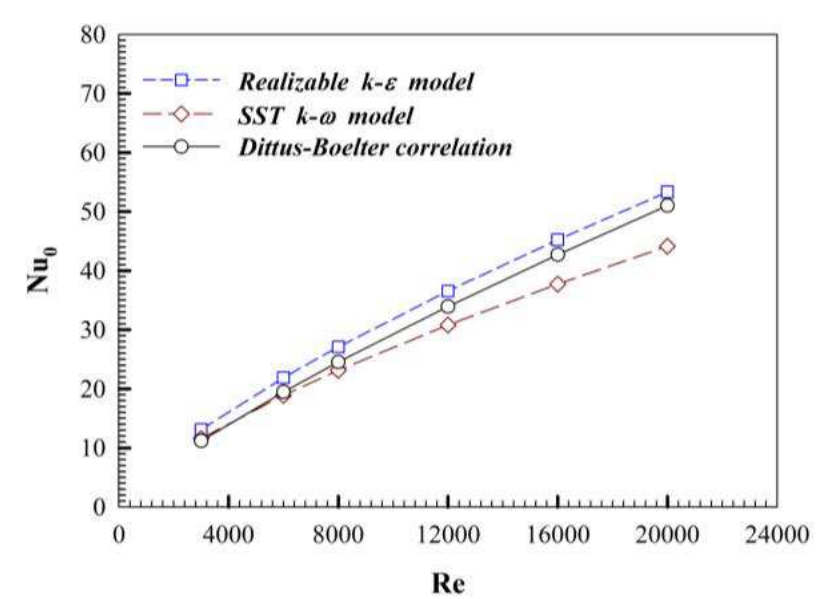

(a)

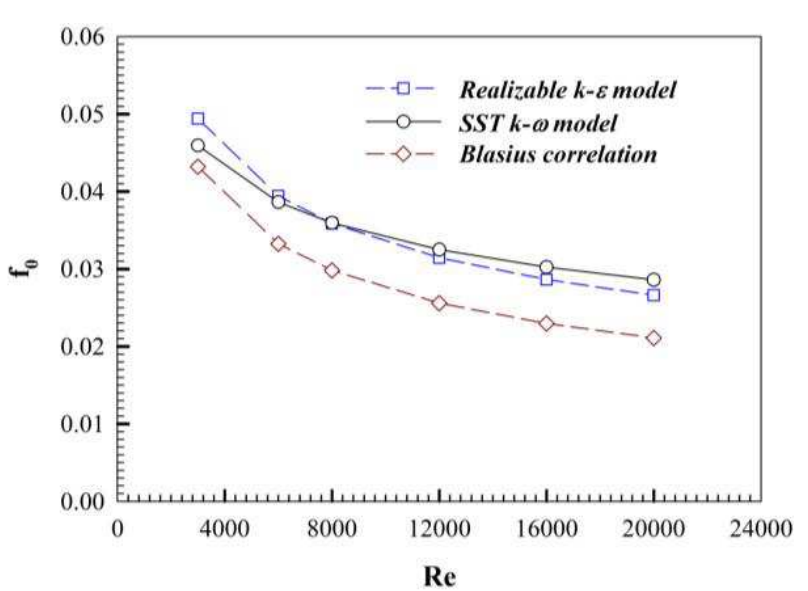

(b)

Fig. 3. Smooth duct proofs for (a) $N u$ and (b) $f$

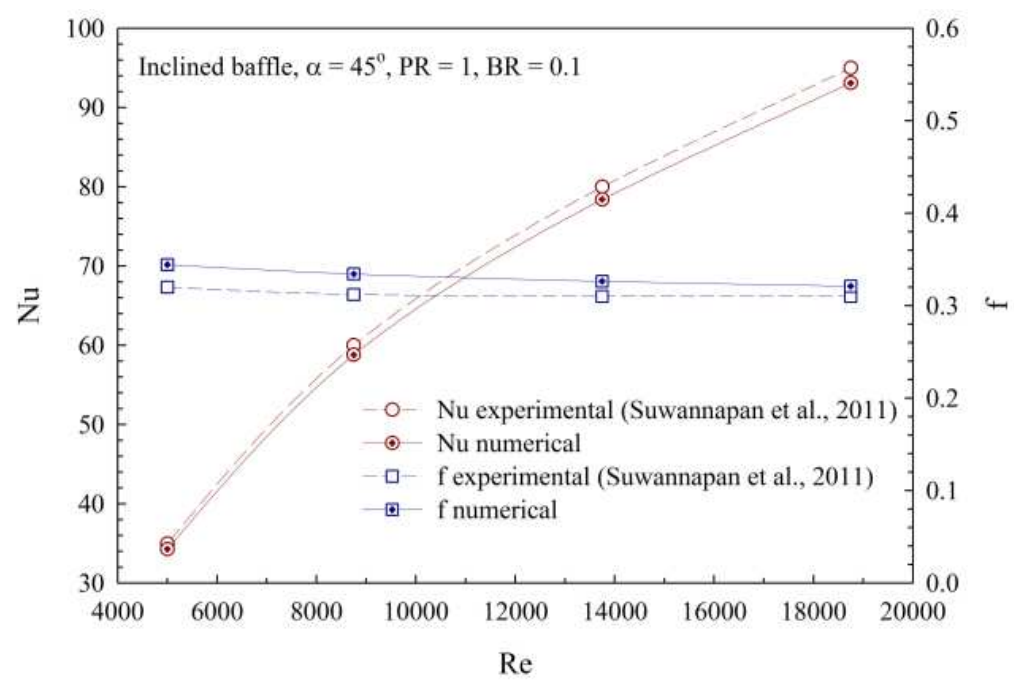

Fig. 4. Comparison between experimental and numerical results for inclined baffle in the square channel at $B R=0.1, P R=1$ and $\alpha=45^{\circ}$

\section{Flow Topology}

The flows in transverse planes and impinging jets on the duct walls are selected to present the flow structures in the heating channel inserted with $D V B$ s. Figure 5a-c report the streamlines in transverse planes at various $x / H$ positions for the $D V B \mathrm{~s}$ in the square duct at $B R=0.05,0.10$ and 0.20 , respectively, $R e=$ 8000 and V-Downstream. As the figures, it is found that the $D V B$ s produce four main vortex flows and small vortices at the corner of the square duct for all case studies. The vortex streams are created through the test section. The symmetry configuration of the flow is found at the upper and lower parts of the planes due to the baffle symmetry.

The DVBs with V-tip pointing upstream produce the flow mechanism as depicted in the Fig. 6a-c, respectively, for $B R=0.05,0.10$ and 0.20 at $R e=$ 8000 . The flow configuration of the $D V B$ s with VUpstream is similar as V-Downstream, but difference in rotational direction. The details of the flows in $y-z$ plane for the $D V B$ s with $\mathrm{V}$-Downstream and VUpstream at various $x / H ; 1,2.25,3.5,4.75$ and 6 , are reported in the Fig. 7. Seeing at the lower pair of the vortex flow (Fig. 8), the DVB with V-Downstream gives counter rotating stream with common-flow-up, while the V-Upstream case performs counter rotating stream with common-flow-down. The vortex flow in the duct promotes a better mixing of the fluid flow between the core of the duct and near the wall regimes that aids to increase the heat transfer rate in the heat exchanger. The difference of the flow structure in the test duct leads to a variation of the heat transfer characteristic. 


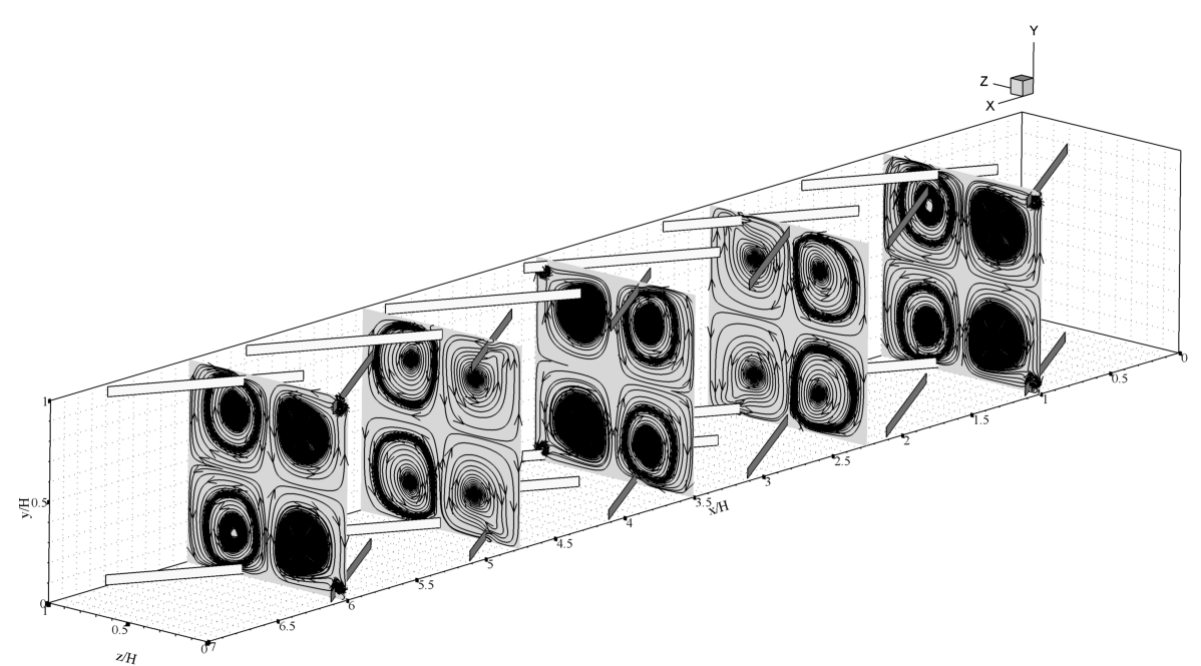

(a)

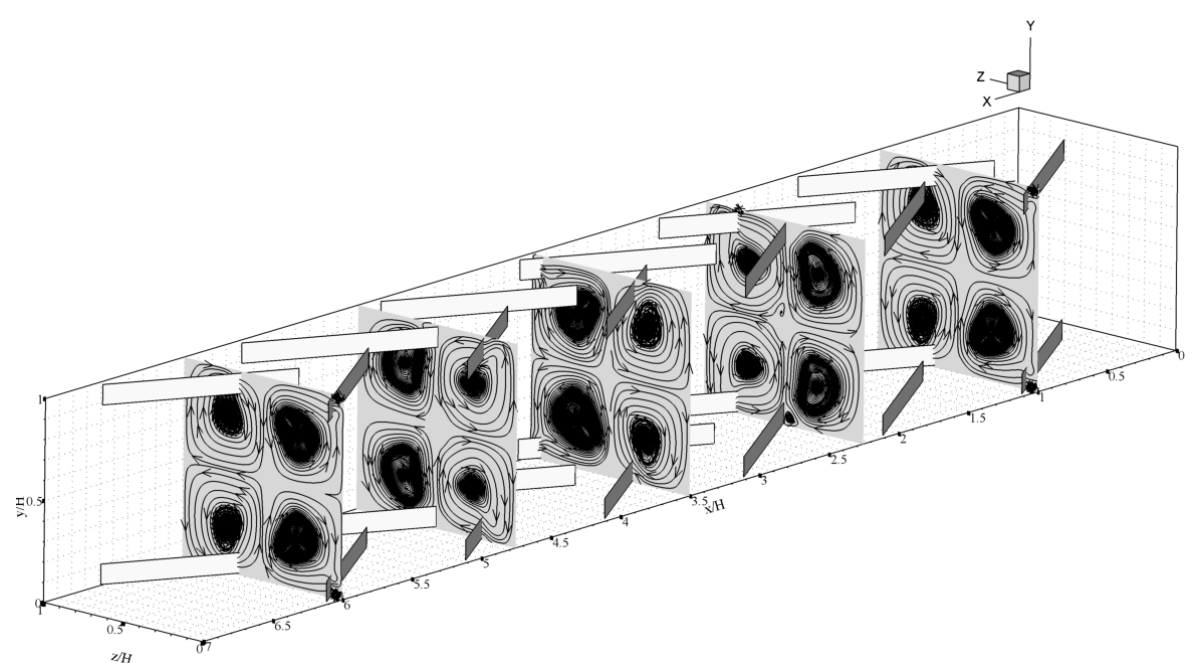

(b)

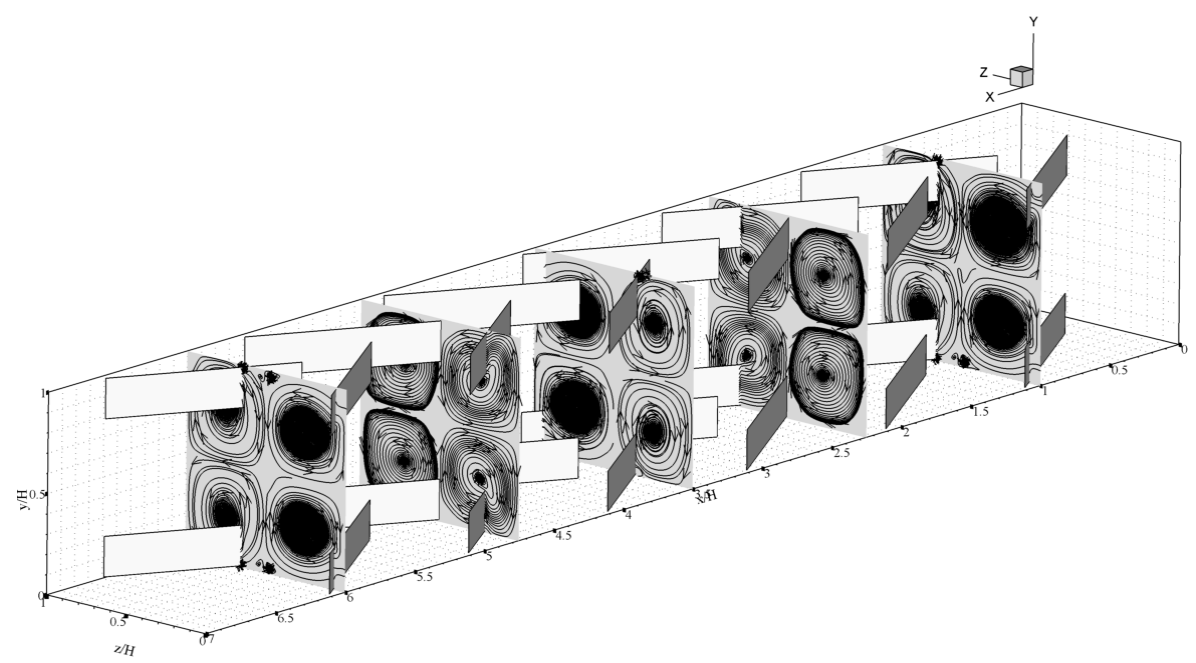

(c)

Fig. 5. Flows in $y-z$ planes of the $D V B \mathrm{~s}$ in the duct for (a) $B R=0.05$, (b) $B R=0.10$ and (c) $B R=0.20$ at $R e=8000$, V-Downstream 


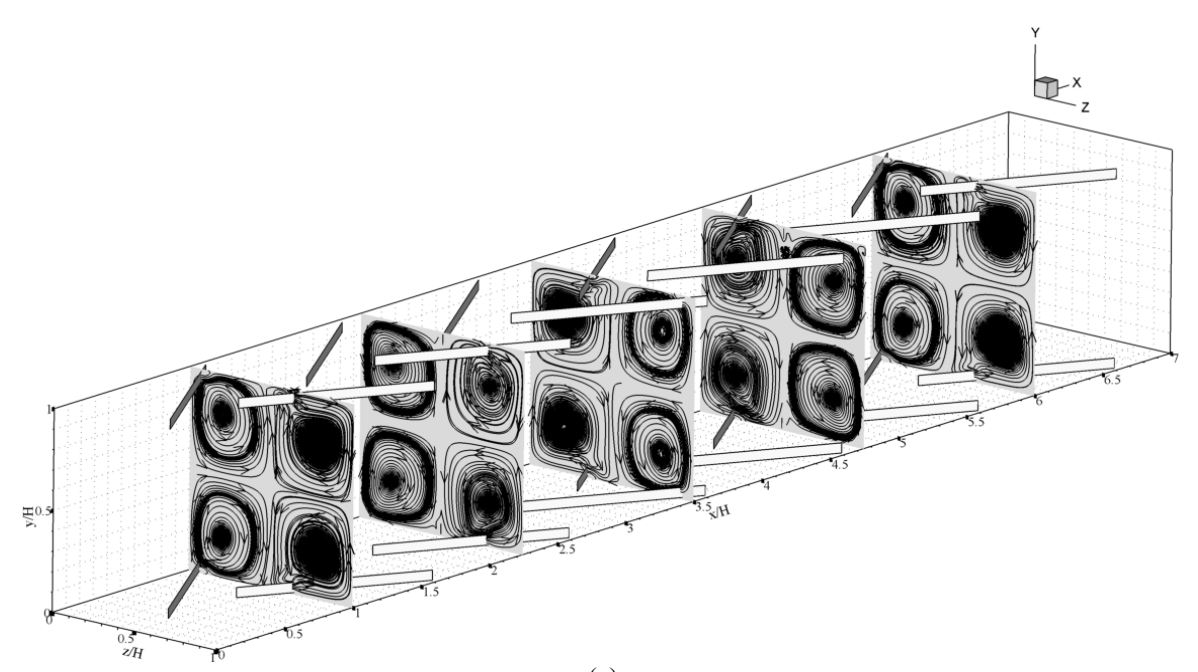

(a)

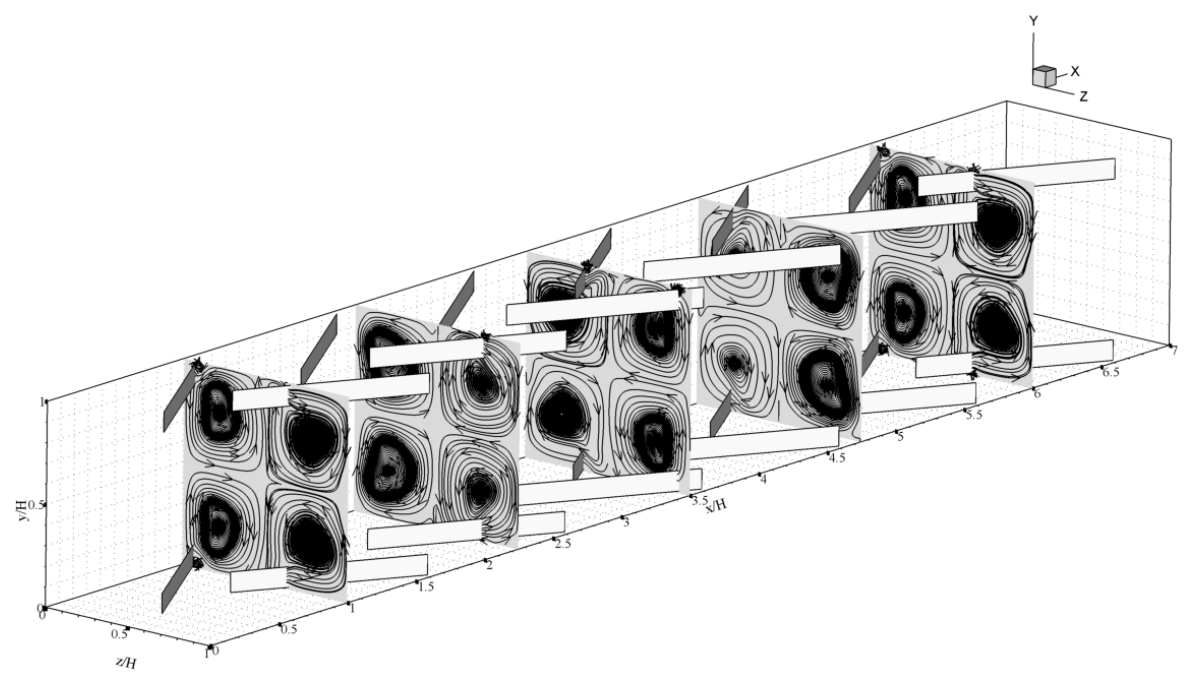

(b)

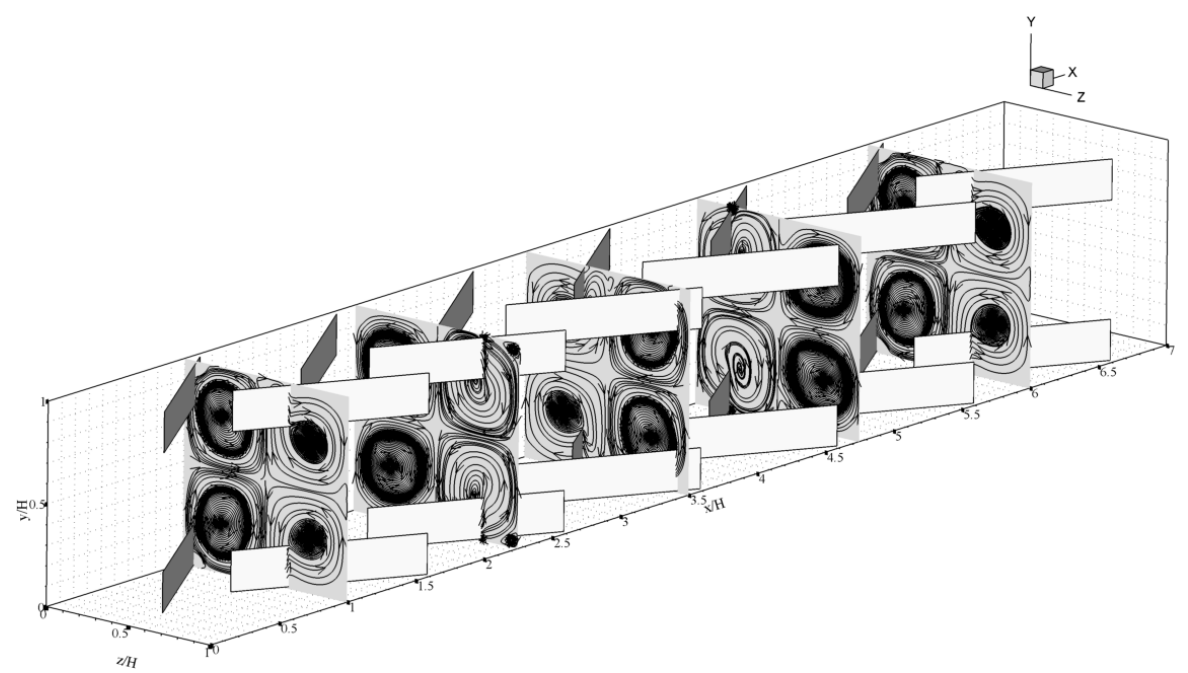

(c)

Fig. 6. Flows in $y-z$ planes of the $D V B \mathrm{~s}$ in the duct for (a) $B R=0.05$, (b) $B R=0.10$ and (c) $B R=0.20$ at $R e=8000$, V-Upstream 

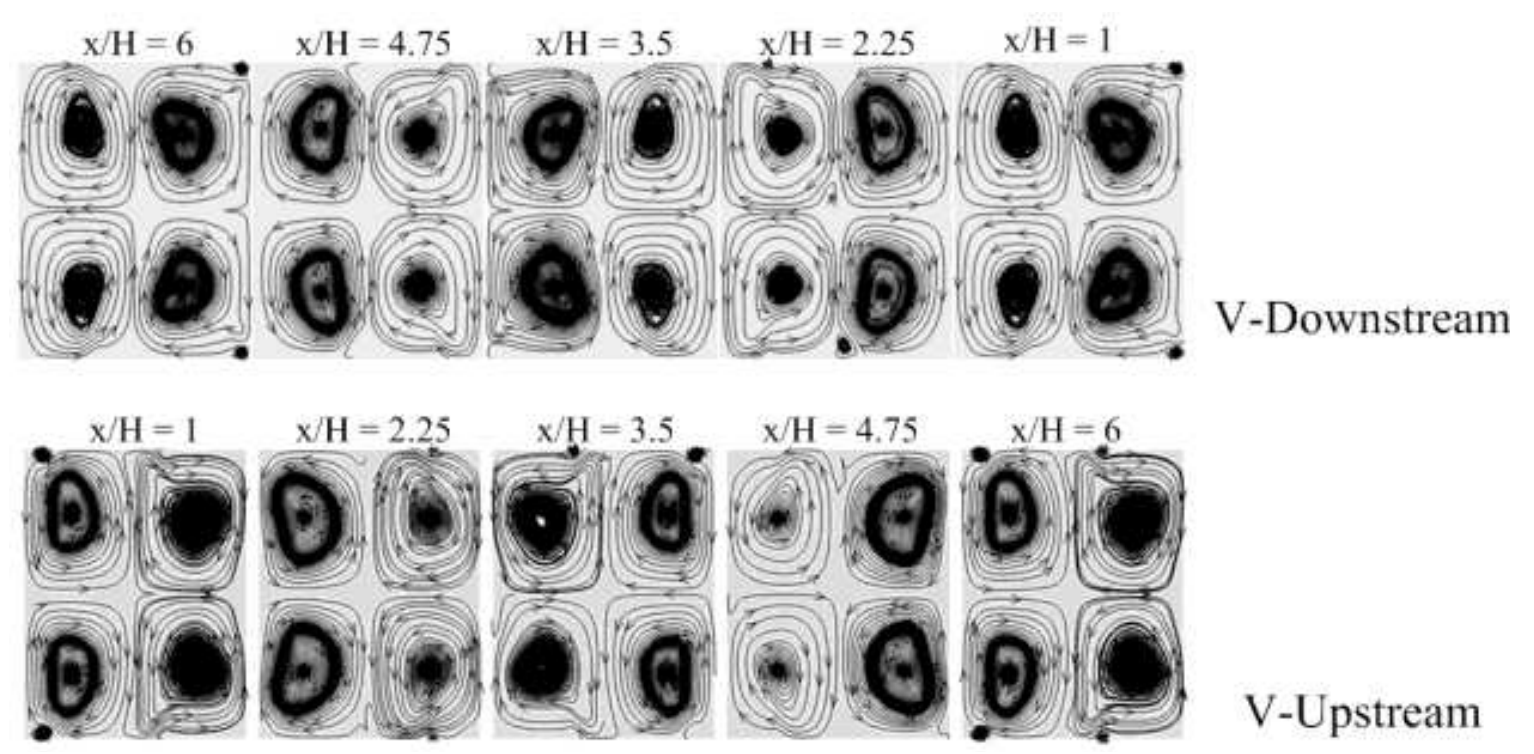

Fig. 7. Detail of flows in $y-z$ planes at various $x / H$ for the $D V B$ s with V-Downstream and V-Upstream
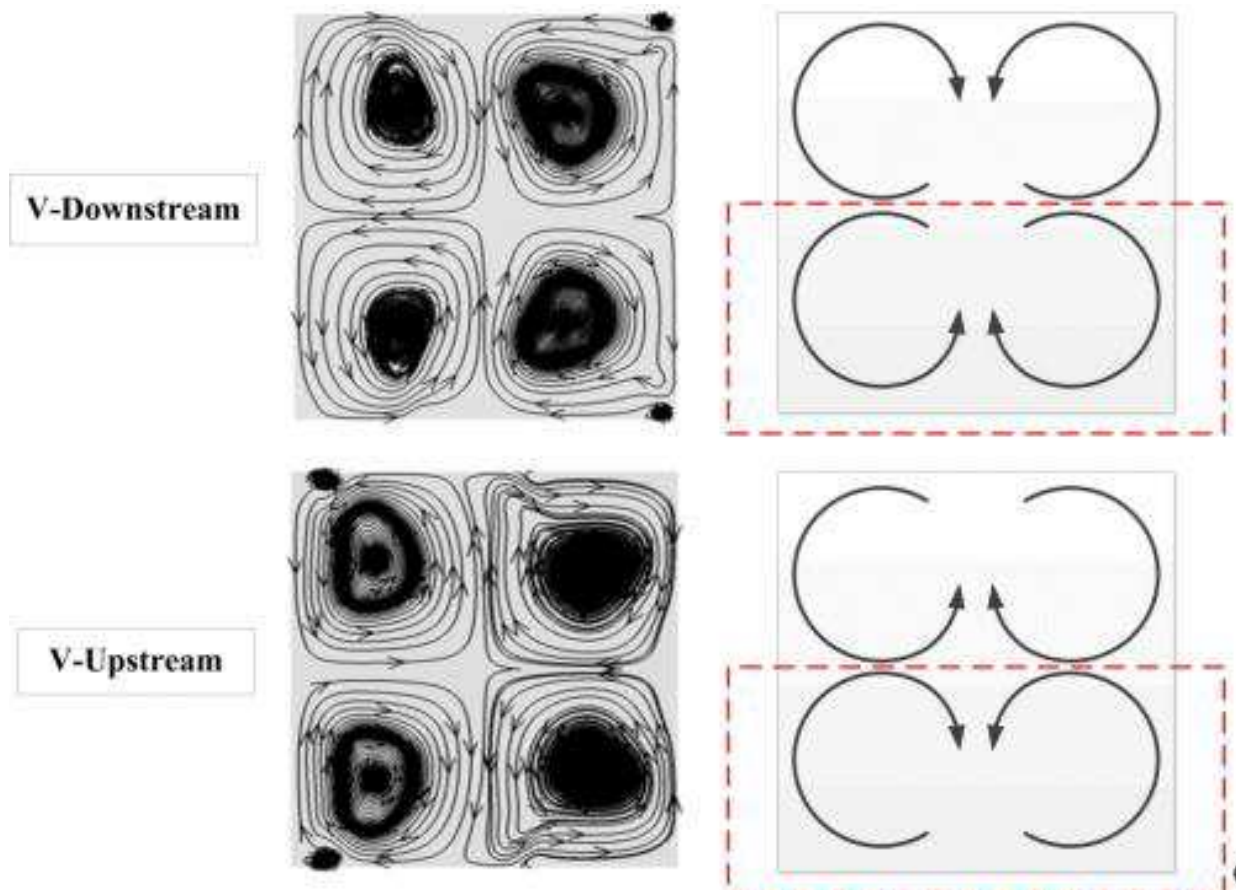

Common-flow-up

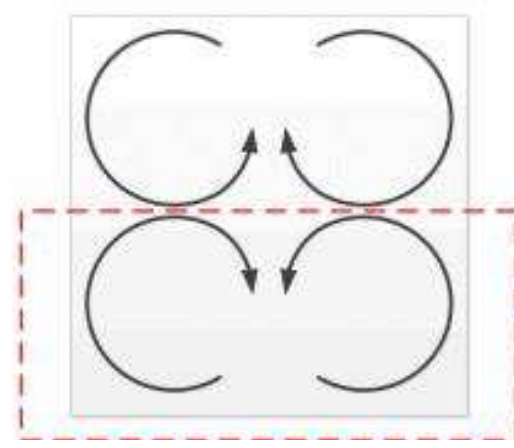

Common-flow-down

Fig. 8. Diagram of the flow structure in $y$-z plane for the $D V B$ s with V-Downstream and V-Upstream

Figures 9 and 10 show the impinging flow on the duct walls with the local Nusselt number distributions for the $D V B$ s with V-Downstream and V-Upstream, respectively, at $B R=0.2$ and $R e=8000$. The impingement of the fluid flow on the duct walls is found in both cases. The impinging regimes perform the highest heat transfer areas, which are plotted by red contours of the Nusselt number. The impingement areas are found at the upper-lower walls and sidewalls for V-Downstream, while are found at the upper-lower walls for V-Upstream. The strength of the flow, which impinging on the wall for V-Upstream, seems to be stronger than the V-Downstream when considering from the $N u_{x}$ contours. The powers of the vortex flow and impinging flow are important keys for the heat transfer augmentation. The increment of the flow strength leads to the rise of the heat transfer rate in the duct heat exchanger. 


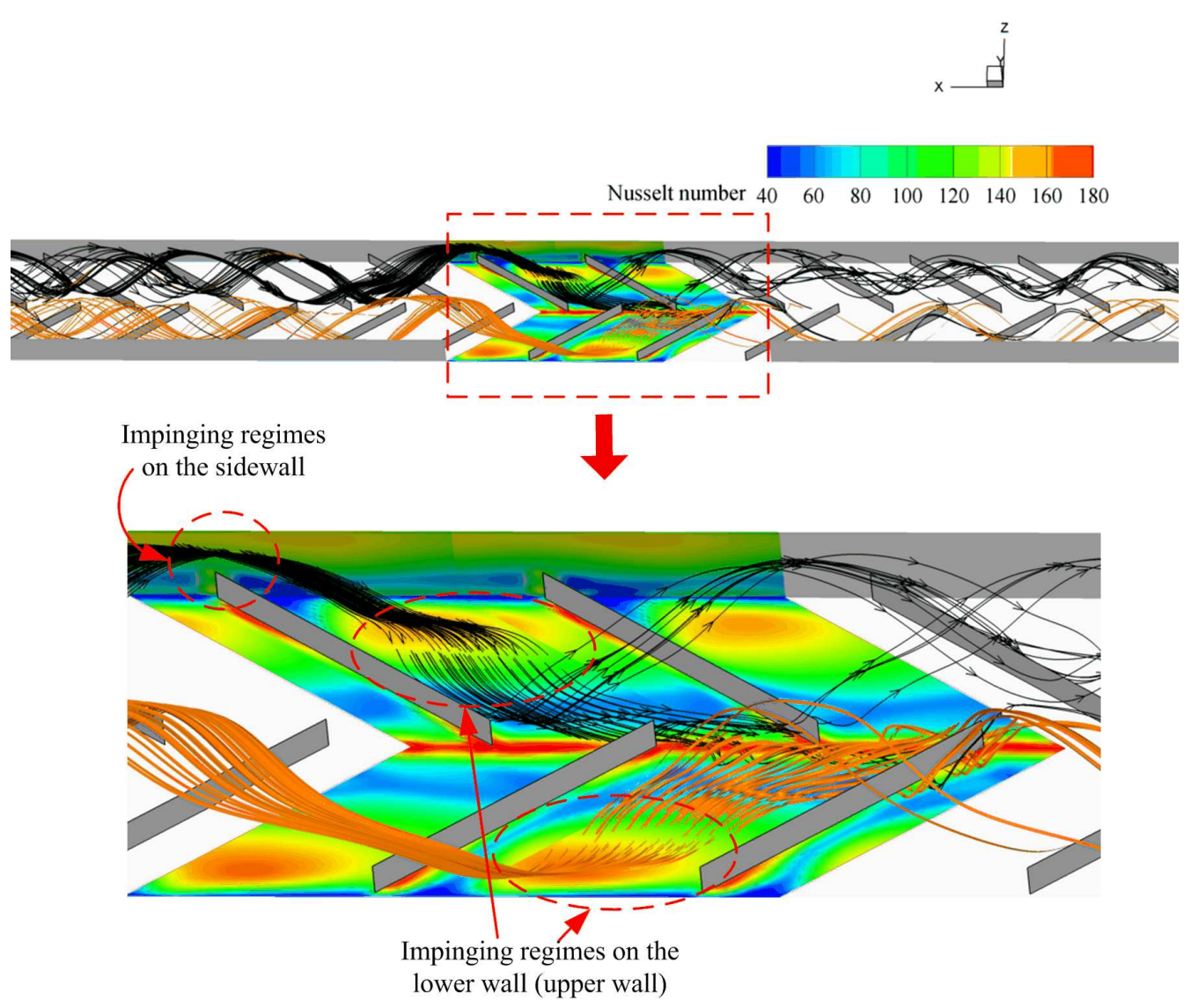

Fig. 9. Impinging flow with $N u_{\mathrm{x}}$ contours on the duct wall for the $D V B \mathrm{~s}$ with V-Downstream

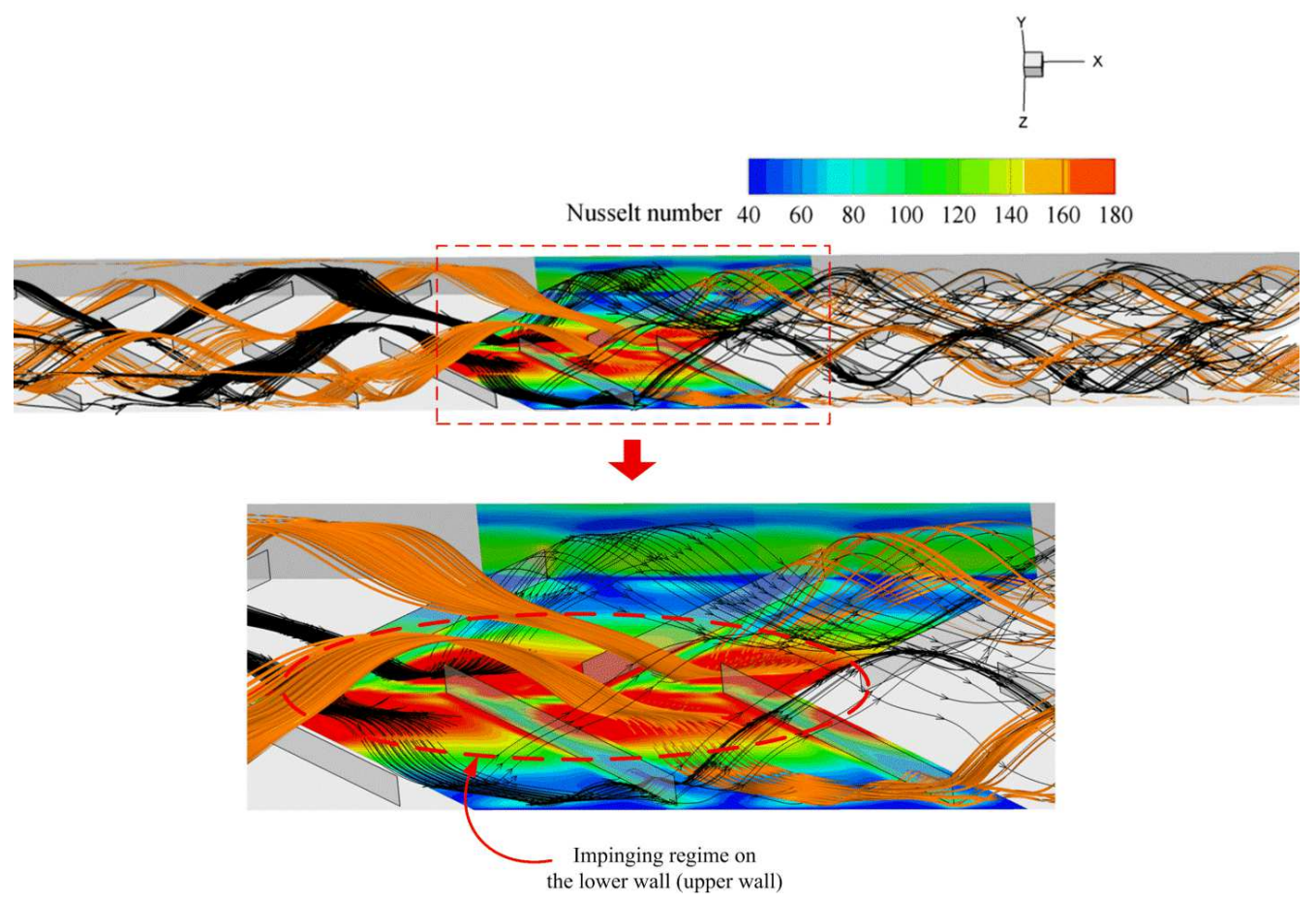

Fig. 10. Impinging flow with $N u_{\mathrm{x}}$ contours on the duct wall for the $D V B \mathrm{~s}$ with V-Upstream 


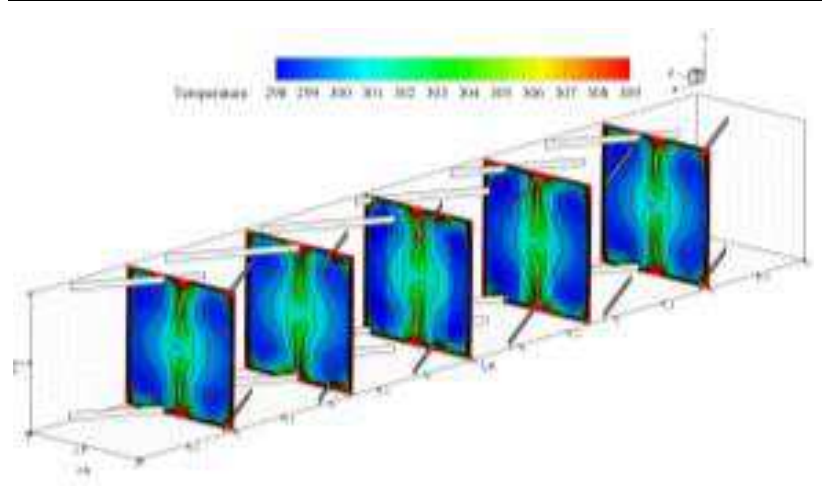

(a)

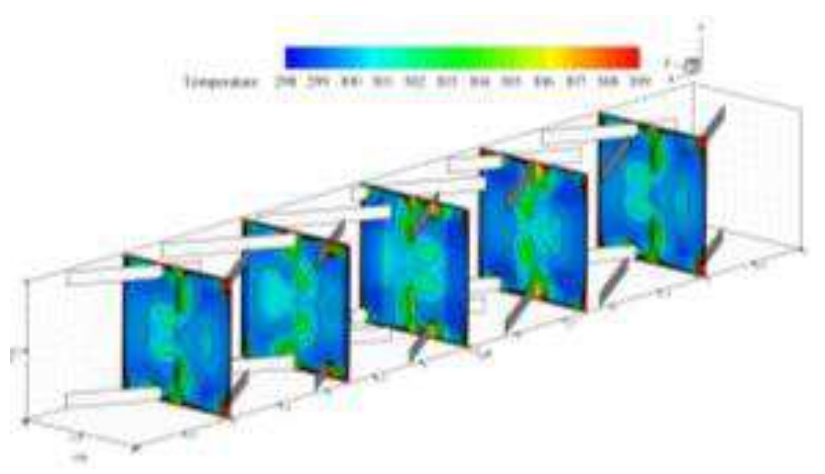

(b)

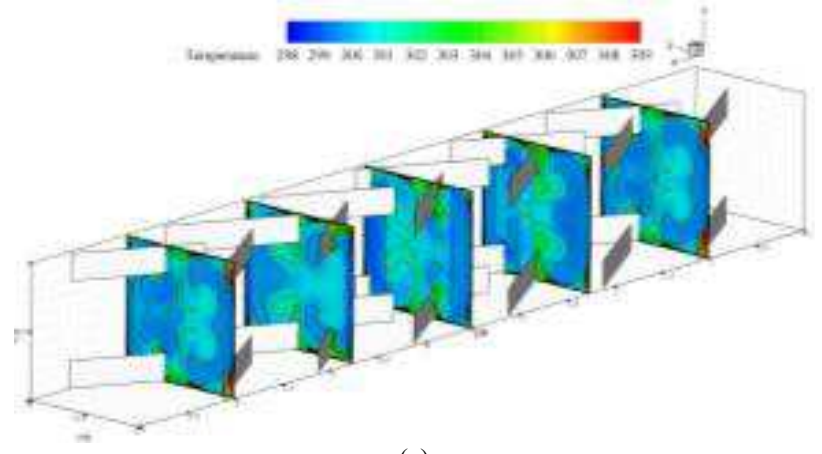

(c)

Fig. 11. Temperature distributions in $y-z$ planes of the $D V B \mathrm{~s}$ in the duct for (a) $B R=0.05$, (b) $B R=0.10$ and (c) $B R=0.20$ at $R e=$ 8000, V-Downstream

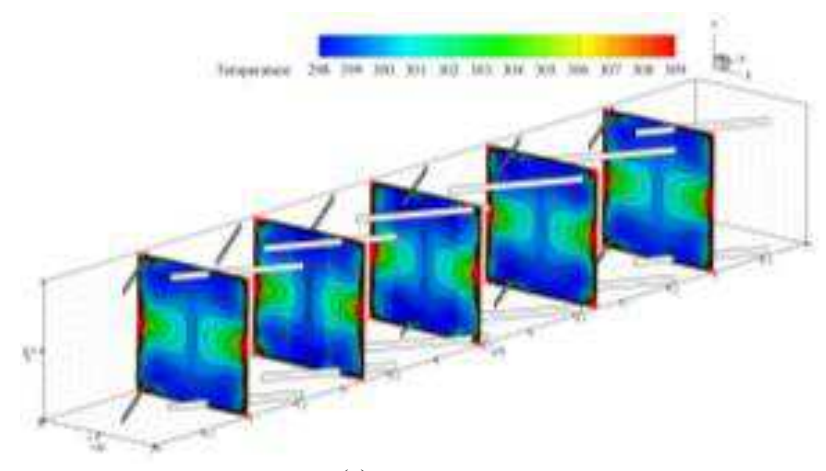

(a)

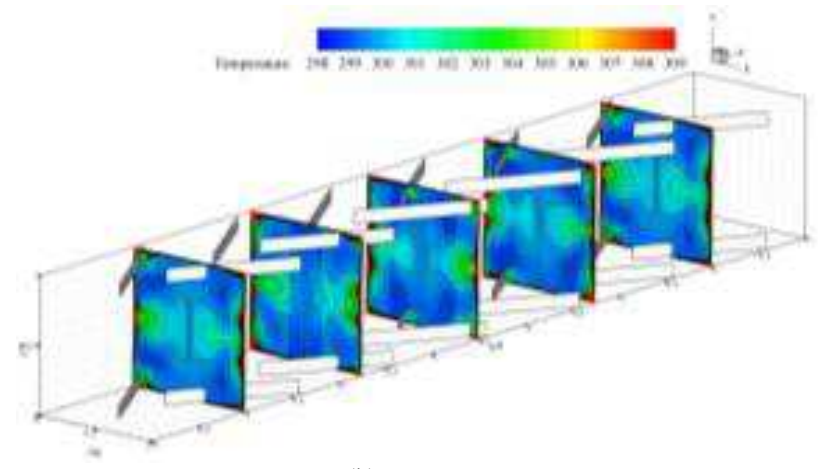

(b)

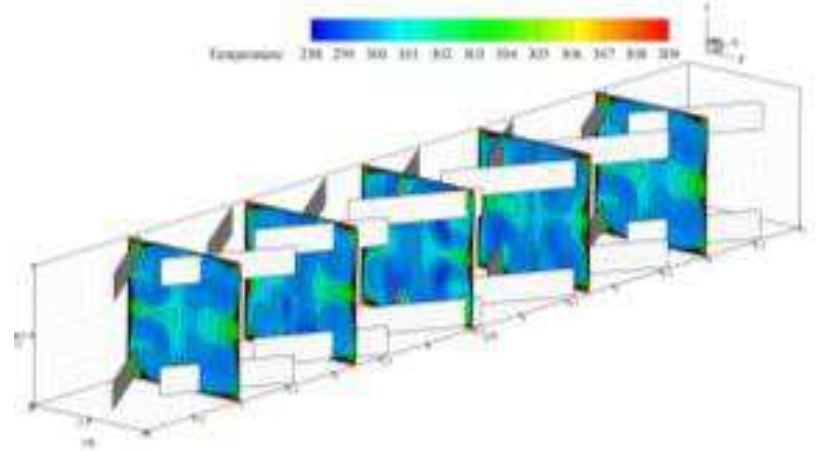

(c)

Fig. 12. Temperature distributions in $y-z$ planes of the $D V B \mathrm{~s}$ in the duct for (a) $B R=0.05$, (b) $B R=0.10$ and (c) $B R=0.20$ at $R e=$ 8000, V-Upstream 

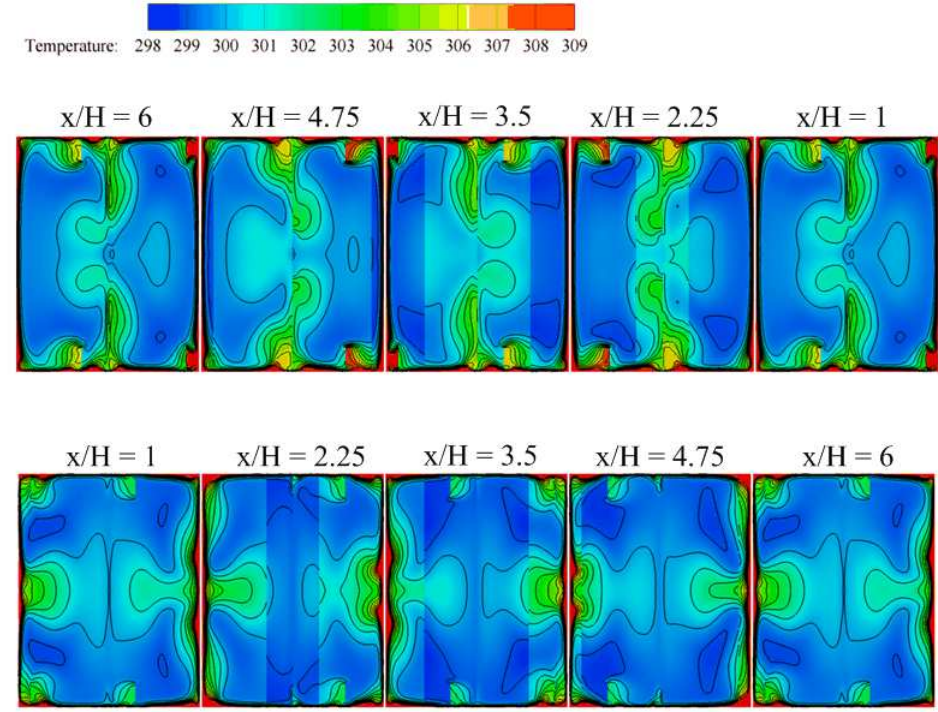

\section{V-Downstream}

\section{V-Upstream}

Fig. 13. Detail of temperature distributions in $y$-z planes at various $x / H$ for the $D V B$ s with V-Downstream and V-Upstream

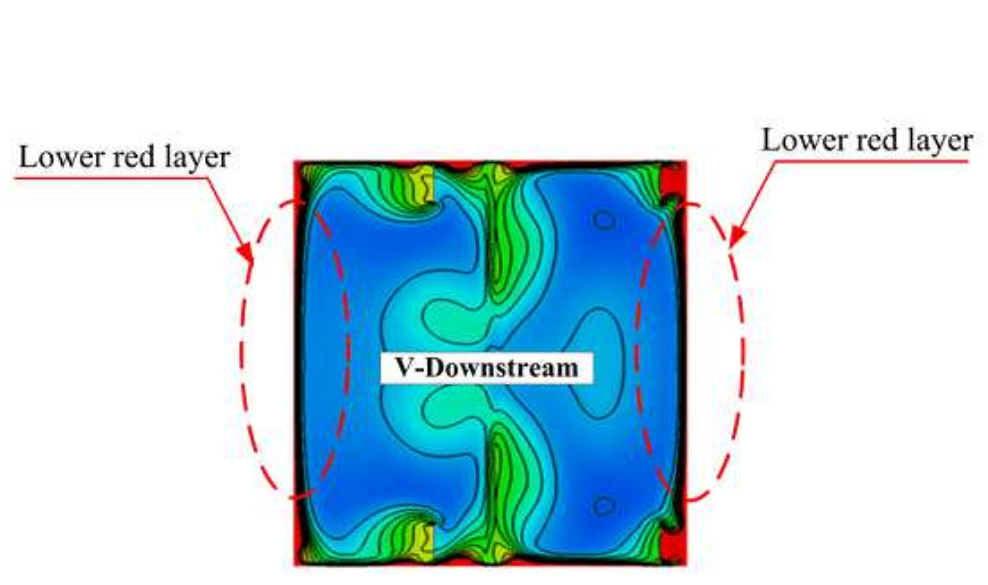

(a)

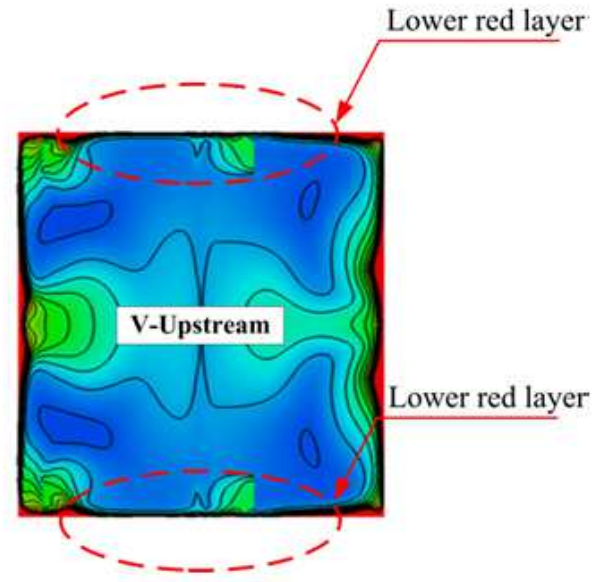

(b)

Fig. 14. The disturbance on the thermal boundary layer near the duct walls by impinging flows for (a) V-Downstream and (b) V-Upstream

\section{Heat Transfer Characteristic}

In this section, the temperature contours in $y$-z axis and the local Nusselt number contours on the channel surfaces are created to help to describe the heat transfer mechanisms in the test channel.

Figures $11 \mathrm{a}-\mathrm{c}$ present the temperature distributions in $y-z$ planes for the square duct with the VDownstream case at $B R=0.05,0.10$ and 0.20 , respectively, $R e=8000$. For the baseline case (smooth duct), the blue contour (low temperature) is found in the middle of the plane, while the red contour (high temperature) is found near the duct walls. The use of the $D V B$ s in the duct heat exchanger leads to a better mixing of the fluid flow for all cases. The red layer of the temperature contours performs thinner, while the blue contour diffuses from the core of the plane. The $B R=0.20$ of the $D V B \mathrm{~s}$ gives the best fluid mixing, while the $B R=0.05$ performs the reverse result. This is because the $B R=0.20$ can produce the highest vortex strength. The similar trend is detected in the case of the V-Upstream as depicted in the Figs. 12a-c for $B R$ $=0.05,0.10$ and 0.20 at $R e=8000$, respectively. The details of the heating distributions in $y-z$ planes are presented in the Fig. 13 on both cases of the DVBs. Considering at each plane, the lower red layer is found at left-right parts and upper-lower parts for VDownstream and V-Upstream, respectively (Fig. 14). The V-Downstream case generates the vortex flows (counter rotating flow with common-flow-up), which impinge on the left-right parts, while the V-Upstream case creates the vortex flows (counter rotating flow with common-flow-down) that interrupt on the upperlower parts of the channel. The difference of the stream configuration effects for the variance of the heat transfer profile in the heating section. 


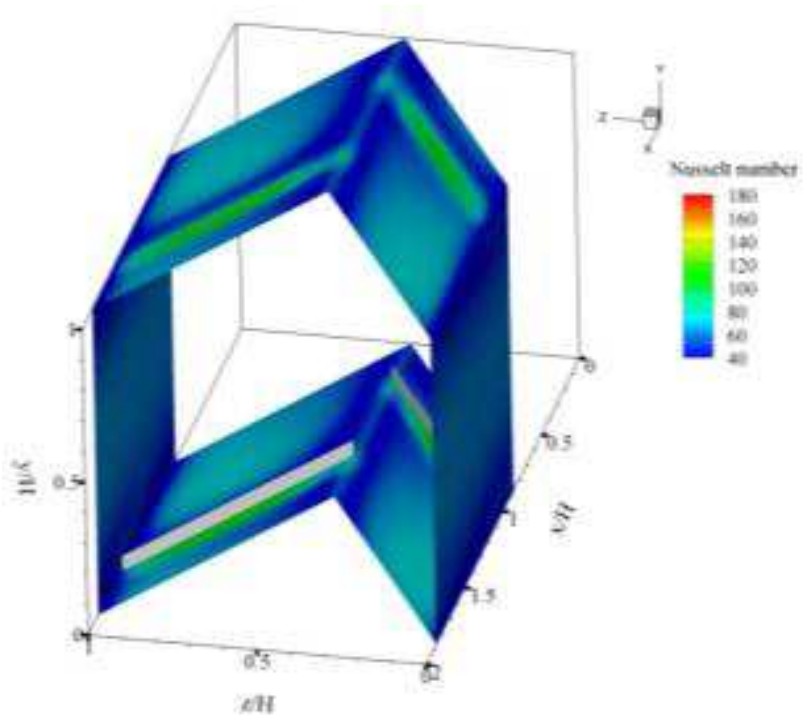

(a)

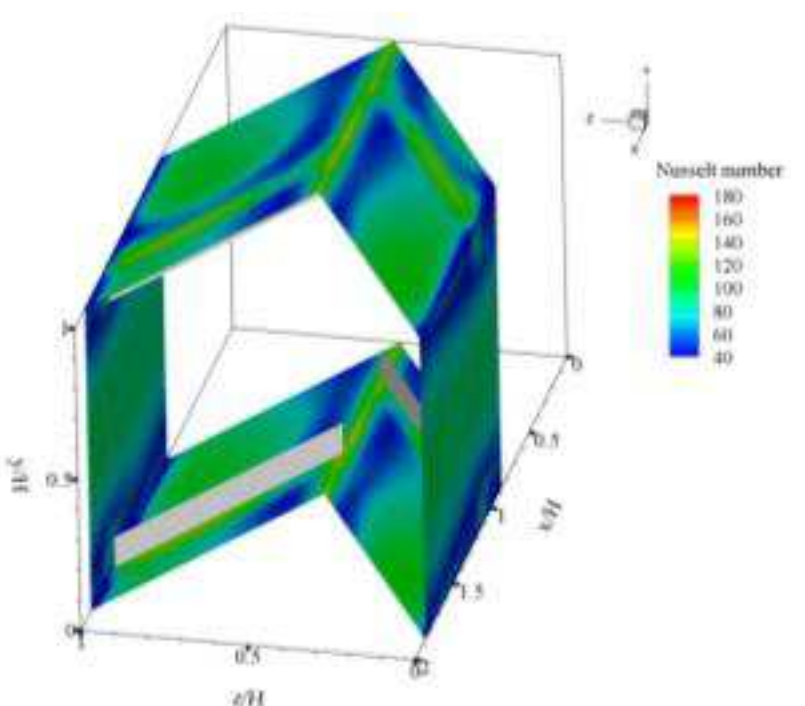

(b)

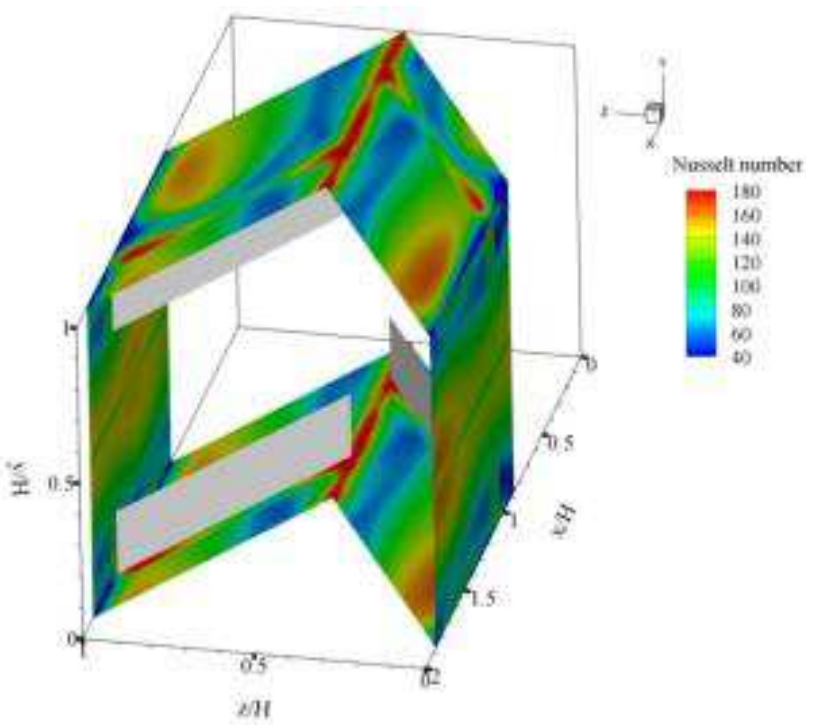

(c)

Fig. 15. $N u_{\mathrm{x}}$ contours on the duct walls of the $D V B \mathrm{~s}$ in the duct for (a) $B R=0.05$, (b) $B R=0.10$ and (c) $B R=0.20$ at $R e=8000$, VDownstream

Figures 15a-c display the local Nusselt number distributions on the duct walls for $B R=0.05,0.10$ and 0.20 , respectively, at $R e=8000, \mathrm{~V}$-Downstream. The heat transfer behavior on the duct walls is found to be nearly pattern for all $B R \mathrm{~s}$. The $B R=0.2$ performs the highest heat transfer coefficient, while the $B R=0.05$ gives an opposite result. This is because the $B R=0.2$ can generate the toughest vortex flow and impinging flow on the duct walls in comparison with other $B R$ s. In addition, the rise of the flow blockage ratio (decrease flow area) effects for the heat transfer augmentation. The enhancement of the blockage ratio yields a higher heat transfer and pressure drop in the test region.
Figures 16a-c present the local Nusselt number distributions on the duct walls for the $D V B$ s with $\mathrm{V}$ Upstream at $B R=0.05,0.10$ and 0.20 , respectively, for $R e=8000$. In general, the heat transfer profile is found similarly in all cases. It is clearly seen that the flow impinges on the upper and lower walls of the duct. The $B R=0.2$ provides the maximum heat transfer rate, while the $B R=0.05$ performs the lowest value.

\section{Performance Assessment}

The $N u / N u_{0}, f l f_{0}$ and $T E F$ are plotted with the Reynolds number as Fig. 17. 


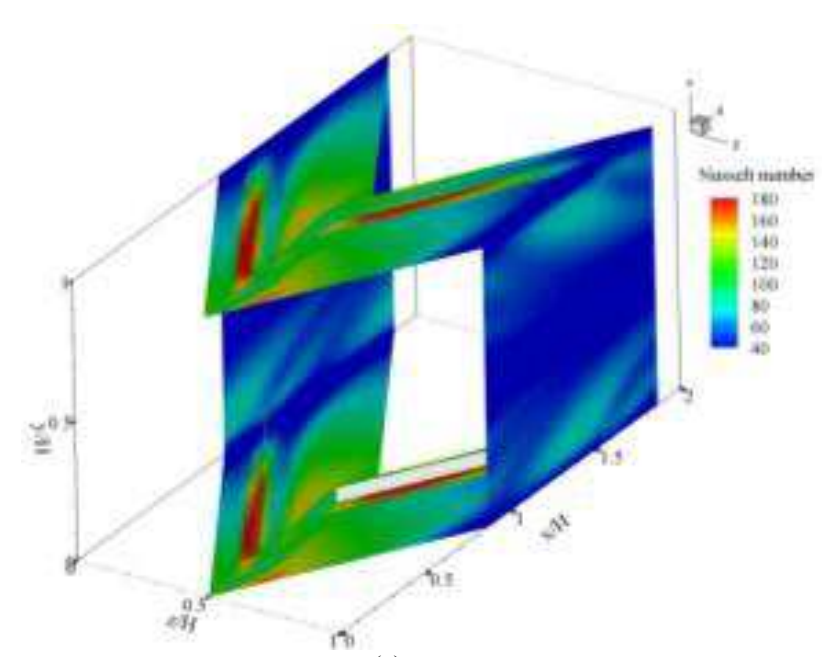

(a)

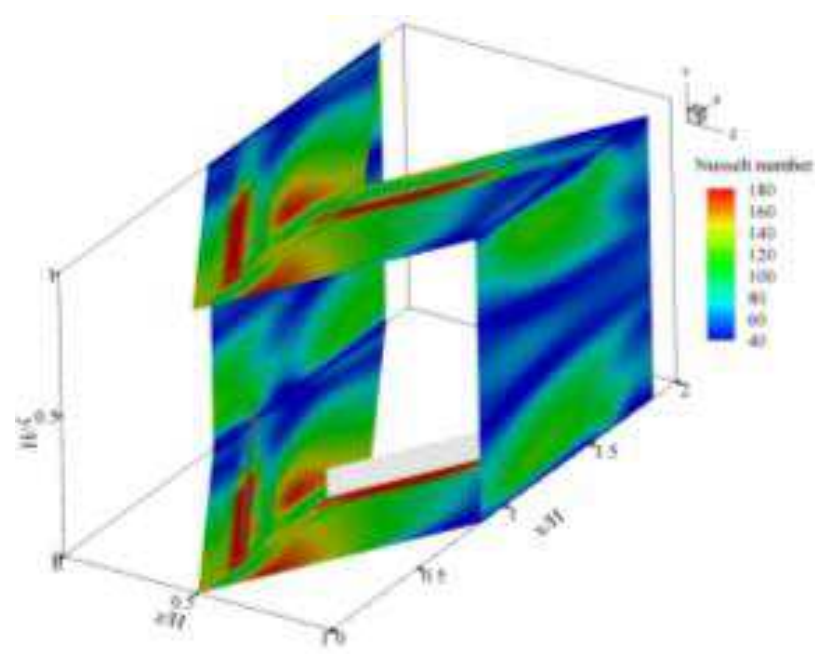

(b)

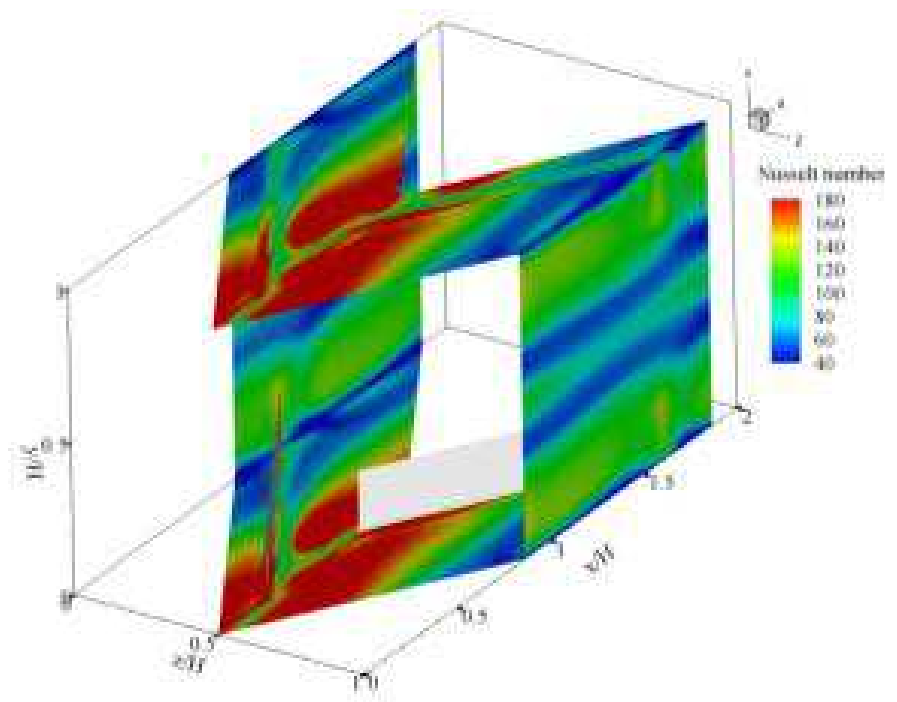

Fig. 16. $N u_{\mathrm{x}}$ contours on the duct walls of the $D V B \mathrm{~s}$ in the duct for (a) $B R=0.05$, (b) $B R=0.10$ and (c) $B R=0.20$ at $R e=8000$, V-Upstream

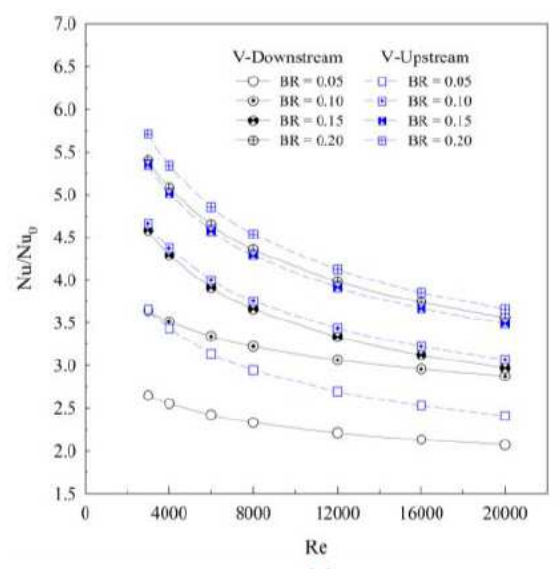

(a)

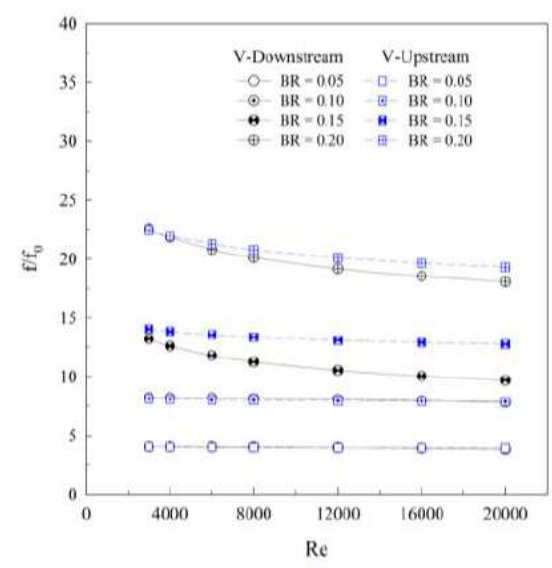

(b)

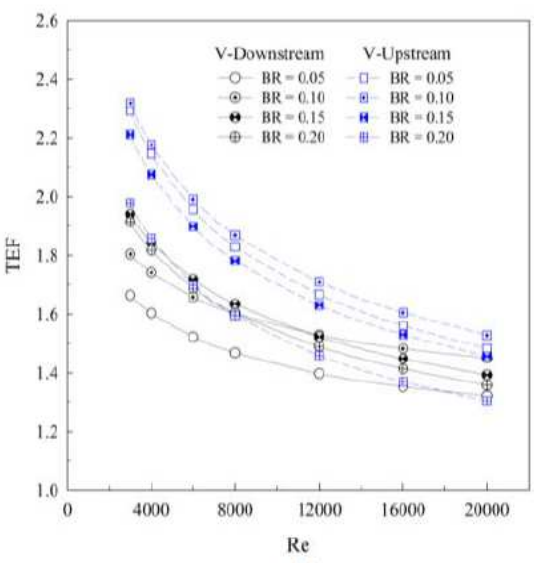

(c)

Fig. 17 (a) $N u / N u_{0}$ Vs $R e$, (b) $f l f_{0}$ Vs $R e$, (c) $T E F$ Vs $R e$ 
Figure 17a displays the plot of the $N u / N u_{0}$ with the Reynolds numbers at various $B R \mathrm{~s}$ for V-Downstream and V-Upstream cases. The peak of heat transfer rate is found at $B R=0.2$ due to the highest vortex strength, while the opposite result is found at $B R=0.05$ for both arrangements. The $\mathrm{V}$-Upstream provides higher heat transfer rate than the $\mathrm{V}$-Downstream for all $B R \mathrm{~s}$. This is because the impinging regime of the jet flows is found in large areas. At $B R=0.05,0.10$ and 0.15 , the difference of the $N u / N u_{0}$ between the $\mathrm{V}$-Downstream and V-Upstream are found in large value, while are found in small value at $B R=0.2$. The maximum heat transfer rate is around 5.45 and 5.75 times higher than the smooth duct for V-Downstream and V-Upstream, respectively, at $B R=0.2$ and $R e=3000$. The $N u / N u_{0}$ is around 2.10-5.45 and 2.50-5.75 for V-Downstream and $\mathrm{V}$-Upstream of the $D V B \mathrm{~s}$, respectively, for $B R=0.05$ 0.20 and $R e=3000-20,000$.

The plot of the $f / f_{0}$ with the Reynolds number at various $B R \mathrm{~s}$ for $\mathrm{V}$-Downstream and $\mathrm{V}$-Upstream of the modified V-shaped baffle in the square duct is reported as the Fig. 17b. Generally, the use of the $D V B$ s leads to higher friction factor than the smooth duct for all cases $\left(f / f_{0}>1\right)$. For V-Downstream, the $f / f_{0}$ tends to slightly decrease when augmenting the Reynolds number for $B R=0.15$ and 0.20 , while the $f / f_{0}$ of the $B R=0.05$ and 0.10 is found to be constant when increasing the Reynolds number. For VUpstream, the $f / f_{0}$ remains constant with increasing the Reynolds number, except for $B R=0.2$. The VDownstream and V-Upstream give nearly values of the friction factor at $B R=0.05$ and 0.10 . The $\mathrm{V}$ Upstream provides higher friction factor than the $\mathrm{V}$ Downstream at $B R=0.15$ for all Reynolds numbers and at $B R=0.2$ when $R e>4000$. In rang investigates, the use of the $D V B$ s in the square duct provides the friction loss around 4-22.5 times higher than the smooth duct with no baffle. The maximum pressure loss is found at $R e=3000$ and $B R=0.2$ for both VDownstream and V-Upstream.

The installation with the modified V-shaped baffle in the duct heat exchanger not only increases in heat transfer rate, but also increases in the pressure loss, especially, at high flow blockage ratio. The highest thermal enhancement factor is the optimum point between the augmentation of the heat transfer rate and the rise of the pressure loss in the heating system. Figure 17c depicts the variation of the TEF with the Reynolds number for the square duct fitted with the $D V B$ s. The $T E F$ decreases with increasing the Reynolds number for all cases. It is clearly seen in the figure that the V-Upstream performs higher TEF than the VDownstream, especially, when $B R<0.2$. The use of the $D V B$ s provides higher pressure loss than the smooth duct for all cases $(T E F>1)$. The optimum $T E F$ is found at $B R=0.15$ and 0.10 for $\mathrm{V}$-Downstream and VUpstream around 1.95 and 2.32, respectively, at $R e=$ 3000. In range studies, the $T E F$ is around 1.3-2.32 depended on $R e, B R$ and flow direction.

\section{Conclusion}

The thermal profile, pressure drop and thermohydraulic performance in the square duct fitted with the $D V B \mathrm{~s}$ for $B R=0.05-0.20, R e=3000-20,000$ of $\mathrm{V}$ Downstream and V-Upstream are presented. The numerical examination is selected to investigate the present problem. The major outcomes are as follows.

The disturbance of the thermal boundary, impinging flow and vortex flow are found when installing the $D V B \mathrm{~s}$ in the heating section.

The decrease of the flow area results in the increasing the heat transfer rate and pressure drop around 2.1-5.75 and 4-22.5 times above the baseline case, respectively.

The best thermal performance is obtained from $B R=$ $0.10, R e=3000, \mathrm{~V}$-Upstream about 2.32 .

The flow and heat transfer visualizations, which reported by the computational investigation, help to find the way to improve the heat applications in the industries. The computational method also helps to save human resource in the study process.

The development of the vortex generators in the heating operation had been studied continuously. The selection of the vortex generators depends on the application of the heat exchanger.

\section{Acknowledgement}

The authors would like to acknowledge Assoc. Prof. Dr. Pongjet Promvonge and Mr. Jaray Wongpueng for suggestions.

\section{Funding Information}

The research was sponsored by King Mongkut's University of Technology North Bangkok Contract no. KMUTNB-GEN-59-62.

\section{Author's Contributions}

Both the authors have equally contributed to this manuscript.

\section{Ethics}

This article is original and contains unpublished material. The corresponding author confirms that all of the other authors have read and approved the manuscript and no ethical issues involved. 


\section{References}

Alam, T., R.P. Saini and J.S. Saini, 2014a. Effect of circularity of perforation holes in V-shaped blockages on heat transfer and friction characteristics of rectangular solar air heater duct. Energy Convers. Manage., 86: 952-963. DOI: 10.1016/j.enconman.2014.06.050

Alam, T., R.P. Saini and J.S. Saini, 2014b. Experimental investigation on heat transfer enhancement due to $\mathrm{V}$-shaped perforated blocks in a rectangular duct of solar air heater. Energy Convers. Manage., 81: 374-383. DOI: 10.1016/j.enconman.2014.02.044

Boonloi, A. and W. Jedsadaratanachai, 2014a. Thermal performance analysis and empirical correlations for laminar forced convection over $30^{\circ} \mathrm{V}$-baffled square channel. Adv. Mech. Eng., 1-16.

DOI: $10.1155 / 2014 / 930272$

Boonloi, A. and W. Jedsadaratanachai, 2014b. Forced convection heat transfer, flow configuration and thermal performance in a square channel with modified V-shaped baffles. J. Math. Statist., 10: 201-210. DOI: 10.3844/jmssp.2014.201.210

Jedsadaratanachai, W. and A. Boonloi, 2014a. Thermal performance assessment for laminar forced convection with downstream reformed-V and reformed-double-V generators. J. Math. Statist., 10: 426-435. DOI: $10.3844 /$ jmssp.2014.426.435

Jedsadaratanachai, W. and A. Boonloi, 2014b. Effects of blockage ratio and pitch ratio on thermal performance in a square channel with $30^{\circ}$ double $\mathrm{V}$ baffles. Case Stud. Thermal Eng., 4: 118-128. DOI: 10.1016/j.csite.2014.08.002

Jedsadaratanachai, W., N. Jayranaiwachira and P. Promvonge, 2015. 3D numerical study on flow structure and heat transfer in a circular tube with Vbaffles. Chinese J. Chem. Eng., 23: 342-349.

DOI: $10.1016 /$ j.cjche.2014.11.006

Karwa, R. and G. Chitoshiya, 2013. Performance study of solar air heater having $\mathrm{v}$-down discrete ribs on absorber plate. Energy, 55: 939-955. DOI: $10.1016 /$ j.energy.2013.03.068

Lee, D.H., D.H. Rhee, K.M. Kim, H.H. Cho and H.K. Moon, 2009. Detailed measurement of heat/mass transfer with continuous and multiple Vshaped ribs in rectangular channel. Energy, 34: 1770-1778. DOI: 10.1016/j.energy.2009.07.011

Noothong, W., S. Suwannapan, C. Thianpong and P. Promvonge, 2015. Enhanced heat transfer in a heat exchanger square-duct with discrete V-finned tape inserts. Chinese J. Chem. Eng., 23: 490-498. DOI: $10.1016 /$ j.cjche.2014.05.018

Patankar, S.V., 1980. Numerical Heat Transfer and Fluid Flow. 1st Edn., Hemisphere Publishing Corporation, Washington, ISBN-10: 0070487405, pp: 197.
Promvonge, P. and S. Kwankaomeng, 2010. Periodic laminar flow and heat transfer in a channel with $45^{\circ}$ staggered V-baffles. Int. Commun. Heat Mass Transfer, 37: 841-849.

DOI: $10.1016 /$ j.icheatmasstransfer.2010.04.002

Promvonge, P., 2010. Heat transfer and pressure drop in a channel with multiple $60^{\circ} \mathrm{V}$-baffles. Int. Commun. Heat Mass Transfer, 37: 835-840. DOI: $10.1016 /$ j.icheatmasstransfer.2010.04.003

Promvonge, P., 2015. Thermal performance in squareduct heat exchanger with quadruple V-finned twisted tapes. Applied Thermal Eng., 91: 298-307. DOI: 10.1016/j.applthermaleng.2015.08.047

Promvonge, P., W. Changcharoen, S. Kwankaomeng and C. Thianpong, 2011. Numerical heat transfer study of turbulent square-duct flow through inline Vshaped discrete ribs. Int. Commun. Heat Mass Transfer, 38: 1392-1399.

DOI: 10.1016/j.icheatmasstransfer.2011.07.014

Promvonge, P., S. Skullong, S. Kwankaomeng and C. Thiangpong, 2012a. Heat transfer in square duct fitted diagonally with angle-finned tape-Part 2: Numerical study. Int. Commun. Heat Mass Transfer, 39: 625-633.

DOI: 10.1016/j.icheatmasstransfer.2012.03.010

Promvonge, P., W. Jedsadaratanachai, S. Kwankaomeng and C. Thianpong, 2012b. 3D simulation of laminar flow and heat transfer in Vbaffled square channel. Int. Commun. Heat Mass Transfer, 39: 85-93.

DOI: 10.1016/j.icheatmasstransfer.2011.09.004

Rajaseenivasan, T., S. Srinivasan and K. Srithar, 2015. Comprehensive study on solar air heater with circular and V-type turbulators attached on absorber plate. Energy, 88: 863-873.

DOI: $10.1016 /$ j.energy.2015.07.020

Suwannapan, S., S. Chokphoemphun, C. Thianpong and P. Promvonge, 2011. Thermal behavior in a square channel with angled ribs. Proceedings of the 2nd TSME International Conference on Mechanical Engineering, Oct. 19-21, Krabi, Thailand, pp: 1-7.

\section{Nomenclature}

$b \quad$ Baffle height, $\mathrm{m}$

$B R$ Blockage ratio, $(b / H)$

$e \quad$ Gap between baffle and duct wall, $\mathrm{m}$

$D_{h} \quad$ Hydraulic diameter of the square duct, m

$H \quad$ Duct height, $\mathrm{m}$

$P R$ Pitch ratio, $(L / H)$

$f \quad$ Friction factor

$h$ Convective heat transfer coefficient, $\mathrm{W} \mathrm{m}{ }^{-2} \mathrm{~K}^{-1}$

$k \quad$ Thermal conductivity of air, $\mathrm{W} \mathrm{m}^{-1} \mathrm{~K}^{-1}$ 
Amnart Boonloi and Withada Jedsadaratanachai / Journal of Mathematics and Statistics 2016, 12 (1): 43.58 DOI: $10.3844 / j m s s p .2016 .43 .58$

$L \quad$ Periodic length (distance between baffles), $\mathrm{m}$

$\mathrm{Nu}$ Nusselt number

$P \quad$ Static pressure, $\mathrm{Pa}$

$P r \quad$ Prandtl number

Re Reynolds number, $\left(\rho u_{0} D / \mu\right)$

$T$ Temperature, $\mathrm{K}$

TEF Thermal performance $\left(N u / N u_{0}\right) /\left(f \mid f_{0}\right)^{1 / 3}$

\section{Greek Letter}

$\mu$ Dynamic viscosity, $\mathrm{kg} \mathrm{s}^{-1} \mathrm{~m}^{-1}$

$\rho$ Density, $\mathrm{kg} \mathrm{m}^{-3}$

$\alpha$ Flow attack angle

\section{Subscript}

0 Smooth duct

pp Pumping power 